\title{
Frailty Index Developed From a Cancer-Specific Geriatric Assessment and the Association With Mortality Among Older Adults With Cancer
}

\author{
Emily J. Guerard, MDª, ; Allison M. Deal, MSc; YunKyung Chang, PhDc; Grant R. Williams, MDº; \\ Kirsten A. Nyrop, PhD ${ }^{\mathrm{b}, \mathrm{c}}$; Mackenzi Pergolotti, PhD, OTR/L,e; Hyman B. Muss, MD ${ }^{\mathrm{b}, \mathrm{c}}$; \\ Hanna K. Sanoff, $\mathrm{MD}^{\mathrm{b}, \mathrm{c}}$; and Jennifer L. Lund, $\mathrm{PhD}^{\mathrm{c}, \mathrm{f}}$
}

\begin{abstract}
Background: An objective measure is needed to identify frail older adults with cancer who are at increased risk for poor health outcomes. The primary objective of this study was to develop a frailty index from a cancer-specific geriatric assessment (GA) and evaluate its ability to predict all-cause mortality among older adults with cancer. Patients and Methods: Using a unique and novel data set that brings together GA data with cancer-specific and long-term mortality data, we developed the Carolina Frailty Index (CFI) from a cancer-specific GA based on the principles of deficit accumulation. CFI scores (range, $0-1)$ were categorized as robust $(0-0.2)$, pre-frail $(0.2-0.35)$, and frail $(>0.35)$. The primary outcome for evaluating predictive validity was all-cause mortality. The Kaplan-Meier method and log-rank tests were used to compare survival between frailty groups, and Cox proportional hazards regression models were used to evaluate associations. Results: In our sample of 546 older adults with cancer, the median age was 72 years, $72 \%$ were women, $85 \%$ were white, and $47 \%$ had a breast cancer diagnosis. Overall, $58 \%$ of patients were robust, $24 \%$ were pre-frail, and $18 \%$ were frail. The estimated 5 -year survival rate was $72 \%$ in robust patients, $58 \%$ in pre-frail patients, and $34 \%$ in frail patients (log-rank test, $P<.0001$ ). Frail patients had more than a 2 -fold increased risk of all-cause mortality compared with robust patients (adjusted hazard ratio, $2.36 ; 95 \% \mathrm{Cl}, 1.51-3.68$ ). Conclusions: The CFI was predictive of all-cause mortality in older adults with cancer, a finding that was independent of age, sex, cancer type and stage, and number of medical comorbidities. The CFI has the potential to become a tool that oncologists can use to objectively identify frailty in older adults with cancer.
\end{abstract}

J Natl Compr Canc Netw 2017;15(7):894-902 doi:10.6004/jnccn.2017.0122

\section{Background}

Frailty is a geriatric syndrome that identifies vulnerable older adults who are at increased risk for hospitalization, institutionalization, and death. ${ }^{1-5}$ These adverse

From the aDivision of Hematology and Oncology, University of Wisconsin, Madison, Wisconsin; 'bivision of Hematology and Oncology, University of North Carolina at Chapel Hill, Chapel Hill, North Carolina; 'Lineberger Comprehensive Cancer Center, University of North Carolina at Chapel Hill, Chapel Hill, North Carolina; ${ }^{d}$ Division of Hematology and Oncology, University of Alabama at Birmingham, Birmingham, Alabama eDepartment of Occupational Therapy, Colorado State University, Fort Collins, Colorado; and ${ }^{\mathrm{f} D e p a r t m e n t}$ of Epidemiology, University of North Carolina at Chapel Hill, Chapel Hill, North Carolina.

Submitted November 15, 2016; accepted for publication March 2, 2017.

Dr. Lund has disclosed that her spouse is employed by GlaxoSmithKline. The remaining authors have disclosed that they have no financial interests, arrangements, affiliations, or commercial interests with the manufacturers of any products discussed in this article or their competitors. Funding for this study was provided by the University Cancer Research Fund (UCRF) of health outcomes may occur in frail older adults with cancer during stressful events such as chemotherapy, radiation, or surgery because frail patients have minimal reserve capacity to recover from acute stressors. ${ }^{6}$

the Lineberger Comprehensive Cancer Center at the University of North Carolina at Chapel Hill; Breast Cancer Research Foundation, New York NY (H.B.M.); John A. Hartford Centers of Excellence in Geriatric Medicine and Training Scholar (E.J.G.); UNC Oncology Clinical Translational Research Training Program (5K12CA120780-08) (G.R.W. and J.L.L.); and NCl of the NIH under Award Number (R25CA116339) (M.P.). Work on this study was supported by the Integrated Cancer Information and Surveillance System (ICISS), UNC Lineberger Comprehensive Cancer Center, with funding provided by the UCRF via the State of North Carolina.

Author contributions: Study design: all authors. Data analysis: Guerard, Deal, Chang, Lund. Data interpretation: all authors. Drafting and approval of manuscript: all authors.

Correspondence: Emily J. Guerard, MD, University of Wisconsin, Division of Hematology and Oncology, 600 Highland Avenue, Madison, WI 537925669. E-mail: eguerard@medicine.wisc.edu 
Therefore, identifying frail older adults with cancer is critical to individualizing treatment decisions and minimizing poor health outcomes. ${ }^{7}$ The health and functional status of older adults with cancer varies widely, independent of chronologic age, and standard performance status measures do not provide an accurate estimation of functional age or likely frailty status. ${ }^{7-9}$ As the incidence of cancer in older adults is expected to increase rapidly, ${ }^{10}$ the importance of having a standardized, valid, and practical definition of oncologic frailty has never been more imperative. This definition is needed before frailty classification can help guide treatment decisions.

In the geriatric literature, there are 2 commonly accepted and validated clinical models of frailty. The first, the phenotype model of frailty, developed from a secondary analysis of the Cardiovascular Health Study, incorporates 5 criteria: unintentional weight loss, weakness measured by grip strength using a handheld dynamometer, self-reported exhaustion, slow gait speed, and low physical activity. ${ }^{3}$ With this model, a patient is considered frail if they meet $\geq 3$ of these criteria. The second model, the deficit accumulation model of frailty, identifies the total number of health deficits (ie, symptoms, signs, disabilities, diseases, abnormal laboratory values) a person has, with an increasing number of health deficits indicating greater frailty. ${ }^{11}$ This method is pragmatic because it relies less on information from any one health deficit and has minimal restrictions on which health deficits are included in the model, provided the deficits cover a range of geriatric domains and syndromes. ${ }^{12}$ Both clinical models of frailty have been shown to be associated with poor health outcomes in the general older adult population and to overlap in their ability to identify frailty. ${ }^{1-3,13,14}$

The cancer-specific geriatric assessment $(\mathrm{GA})^{15}$ is a multidimensional assessment that combines patientreported and healthcare provider-administered questionnaires to evaluate geriatric domains and is recommended for every older adult with cancer. ${ }^{16,17}$ The cancer-specific GA is known to identify deficits in patients with a normal Karnofsky performance status and is predictive of treatment-related toxicity in older adults with solid tumors. ${ }^{9,18,19}$ The GA is widely used in geriatric oncology research; however, it has had limited uptake among oncologists in clinical practice. The primary objective of this study was to develop a practical frailty index using a cancer-specific
GA based on the principles of deficit accumulation and to evaluate its ability to predict all-cause mortality among older adults with cancer.

\section{Patients and Methods}

\section{Sample}

The Carolina Senior: UNC Registry for Older Patients (CSR) is an institutional database that contains cross-sectional GA data from older adults (age $\geq 65$ years) with cancer (ClinicalTrials.gov identifier: NCT01137825). The CSR recruits patients diagnosed with any cancer type and at any phase of cancer care (newly diagnosed before treatment, during treatment, after treatment). The cancer-specific GA used in the CSR has been proven feasible in the academic, community, and cooperative group settings. ${ }^{15,20,21}$ This GA contains valid and reliable measures of geriatric domains, including instrumental activities of daily living (IADLs), physical function, number of medications, comorbidities, nutritional status, mental health, social activity and support, and cognitive function..$^{15}$ The CSR began enrolling patients in 2009, and informed consent was obtained for each participant before completing a one-time GA. For this study, patients enrolled in the CSR from 2009 to 2014 from the North Carolina Cancer Hospital, a large academic medical center, were linked to the North Carolina Central Cancer Registry (NCCCR) to obtain tumor-specific data and vital status. The Institutional Review Board of the University of North Carolina separately approved the CSR and data linkage including this frailty data analysis.

\section{Cancer Characteristics}

The NCCCR collects data on all cancers diagnosed in North Carolina. Tumor-specific data (through 2013) and all-cause and cancer-specific mortality (through August 2015) were obtained from NCCCR. Cancer type was obtained using the International Classification of Diseases for Oncology (ICD-O) codes and collapsed into broader cancer categories (eg, breast, lung, gastrointestinal). The date of cancer diagnosis and staging information according to the AJCC 6th Edition was also obtained.

\section{Frailty Measure}

We developed the Carolina Frailty Index (CFI) using the CSR cancer-specific GA based on the principles 
Guerard et al

of deficit accumulation originally described by Rockwood et al. ${ }^{1}$ Our framework for creating the frailty index from CSR data was previously described by Searle et al. ${ }^{12}$ To create our CFI, we selected variables from the GA that were generally known to be associated with health status and that increased in frequency with aging. In addition, as previously reported by Searle et al, ${ }^{12}$ variables in the frailty index need to cover multiple geriatric domains, and the index needs to include 30 to 40 variables to accurately predict outcomes of clinical interest. Using this methodology, we identified 36 variables from the GA for our CFI, with a focus on patient-reported single-item questions concerning IADLs, physical function, comorbidities, number of daily medications, vision, hearing, nutrition, mental health, and social activity. ${ }^{15}$ In addition, we included an objective measure of physical function (Timed $U p$ and Go test) ${ }^{22}$ and cognition (Blessed Orientation-MemoryConcentration test), ${ }^{23}$ originally assessed by a trained clinical research assistant. Each variable in the CFI was scored from 0 to 1 , with a higher score indicating the presence of a health deficit (Table 1).

Participants who reported $<18$ of the 36 variables in the CFI $(n=7 ; 1 \%)$ were excluded from this analysis. Of the remaining 546 patients, 96\% reported $>32$ variables. Scores were calculated by summing the number of positive responses and dividing by the total number of items completed to obtain a final score between 0 and 1 . For patients with missing variables, the total number of variables completed was used as the denominator. CFI scores were categorized as robust $(0-0.2)$, pre-frail $(0.2-0.35)$, and frail $(>0.35)$.

\section{Primary Outcome}

The primary outcome for the predictive validity analysis was all-cause mortality assessed after the date of GA completion. The NCCCR obtains mortality data through annual linking to the National Death Index, Social Security Death Index, and North Carolina State Center for Vital Statistics using name, date of birth, and social security number. As a secondary outcome, we also evaluated the CFI's ability to predict cancer-specific mortality, recorded as the primary cause of death on the state death certificate.

\section{Statistical Analysis}

Descriptive statistics are provided in Table 2 for the entire sample and subdivided by frailty status

\begin{tabular}{|c|c|c|c|c|}
\hline $\begin{array}{l}\text { GA } \\
\text { Domains }\end{array}$ & Variable & Response & Scoring & $\begin{array}{l}\% \text { Positive } \\
\text { Response }\end{array}$ \\
\hline \multirow{48}{*}{$\begin{array}{l}\text { Instrumental } \\
\text { activities of } \\
\text { daily living } \\
\text { and function }\end{array}$} & \multicolumn{4}{|c|}{ Can you use a telephone? } \\
\hline & & Without help & 0 & 97 \\
\hline & & With some help & 1 & 3 \\
\hline & & Unable & 1 & * \\
\hline & \multicolumn{4}{|c|}{ Can you get to places out of walking distance? } \\
\hline & & Without help & 0 & 85 \\
\hline & & With some help & 1 & 15 \\
\hline & & Unable & 1 & * \\
\hline & \multicolumn{4}{|c|}{ Can you go shopping for groceries or clothes? } \\
\hline & & Without help & 0 & 84 \\
\hline & & With some help & 1 & 16 \\
\hline & & Unable & 1 & * \\
\hline & \multicolumn{4}{|c|}{ Can you prepare your own meals? } \\
\hline & & Without help & 0 & 85 \\
\hline & & With some help & 1 & 12 \\
\hline & & Unable & 1 & 3 \\
\hline & \multicolumn{4}{|c|}{ Can you do housework? } \\
\hline & & Without help & 0 & 69 \\
\hline & & With some help & 1 & 27 \\
\hline & & Unable & 1 & 4 \\
\hline & \multicolumn{4}{|c|}{ Can you take your own medicines? } \\
\hline & & Without help & 0 & 92 \\
\hline & & With some help & 1 & 8 \\
\hline & & Unable & 1 & * \\
\hline & \multicolumn{4}{|c|}{ Can you handle your own money? } \\
\hline & & Without help & 0 & 90 \\
\hline & & With some help & 1 & 10 \\
\hline & & Unable & 1 & * \\
\hline & \multicolumn{4}{|c|}{ Can you lift or carry groceries? } \\
\hline & & Not limited at all & 0 & 66 \\
\hline & & Limited a little & 1 & 22 \\
\hline & & Limited a lot & 1 & 12 \\
\hline & \multicolumn{4}{|c|}{ Can you climb one flight of stairs? } \\
\hline & & Not limited at all & 0 & 71 \\
\hline & & Limited a little & 1 & 17 \\
\hline & & Limited a lot & 1 & 12 \\
\hline & \multicolumn{4}{|c|}{ Can you bend, kneel, or stoop? } \\
\hline & & Not limited at all & 0 & 49 \\
\hline & & Limited a little & 1 & 36 \\
\hline & & Limited a lot & 1 & 15 \\
\hline & \multicolumn{4}{|c|}{ Can you walk one block? } \\
\hline & & Not limited at all & 0 & 75 \\
\hline & & Limited a little & 1 & 14 \\
\hline & & Limited a lot & 1 & 12 \\
\hline & \multicolumn{4}{|c|}{ Can you bath or dress yourself? } \\
\hline & & Not limited at all & 0 & 89 \\
\hline & & Limited a little & 1 & 7 \\
\hline & & Limited a lot & 1 & 4 \\
\hline
\end{tabular}

(continued on next page) 
Frailty and Older Adults With Cancer

\section{Table 1. Carolina Frailty Index Variables and Scoring (cont.)}

\begin{tabular}{|c|c|c|c|c|}
\hline $\begin{array}{l}\text { GA } \\
\text { Domains }\end{array}$ & Variable & Response & Scoring & $\begin{array}{l}\text { \% Positive } \\
\text { Response }\end{array}$ \\
\hline \multirow{9}{*}{$\begin{array}{l}\text { Overall } \\
\text { health }\end{array}$} & \multicolumn{4}{|c|}{ Self-reported health } \\
\hline & & Normal & 0 & 28 \\
\hline & & $\begin{array}{l}\text { Minor symptoms of } \\
\text { disease }\end{array}$ & 0 & 33 \\
\hline & & $\begin{array}{l}\text { Some symptoms of } \\
\text { disease }\end{array}$ & 0.5 & 20 \\
\hline & & Care for self only & 1 & 7 \\
\hline & & $\begin{array}{l}\text { Require occasional } \\
\text { assistance }\end{array}$ & 1 & 10 \\
\hline & & $\begin{array}{l}\text { Require } \\
\text { considerable } \\
\text { assistance }\end{array}$ & 1 & 3 \\
\hline & & Disabled & 1 & * \\
\hline & & Severely disabled & 1 & * \\
\hline \multirow{6}{*}{$\begin{array}{l}\text { Physical } \\
\text { function }\end{array}$} & \multicolumn{4}{|c|}{ Falls in the last 6 months } \\
\hline & & 0 & 0 & 76 \\
\hline & & $\geq 1$ & 1 & 24 \\
\hline & \multicolumn{4}{|c|}{ Timed Up and Go test ${ }^{a}$} \\
\hline & & $<14$ seconds & 0 & 67 \\
\hline & & $\geq 14$ seconds & 1 & 33 \\
\hline \multirow{30}{*}{ Comorbidity } & \multicolumn{4}{|c|}{ Other cancers or leukemia } \\
\hline & & No & 0 & 71 \\
\hline & & Yes & 1 & 29 \\
\hline & \multicolumn{4}{|c|}{ Arthritis or rheumatism } \\
\hline & & No & 0 & 48 \\
\hline & & Yes & 1 & 52 \\
\hline & \multicolumn{4}{|l|}{ Glaucoma } \\
\hline & & No & 0 & 91 \\
\hline & & Yes & 1 & 9 \\
\hline & \multicolumn{4}{|c|}{ Emphysema or chronic bronchitis } \\
\hline & & No & 0 & 94 \\
\hline & & Yes & 1 & 7 \\
\hline & \multicolumn{4}{|c|}{ High blood pressure } \\
\hline & & No & 0 & 50 \\
\hline & & Yes & 1 & 50 \\
\hline & \multicolumn{4}{|c|}{ Heart disease } \\
\hline & & No & 0 & 82 \\
\hline & & Yes & 1 & 18 \\
\hline & \multicolumn{4}{|c|}{ Circulation trouble in arms or legs } \\
\hline & & No & 0 & 79 \\
\hline & & Yes & 1 & 21 \\
\hline & \multicolumn{4}{|l|}{ Diabetes } \\
\hline & & No & 0 & 81 \\
\hline & & Yes & 1 & 19 \\
\hline & \multicolumn{4}{|c|}{ Stomach or intestinal disorders } \\
\hline & & No & 0 & 83 \\
\hline & & Yes & 1 & 17 \\
\hline & \multicolumn{4}{|c|}{ Osteoporosis } \\
\hline & & No & 0 & 83 \\
\hline & & Yes & 1 & 17 \\
\hline
\end{tabular}

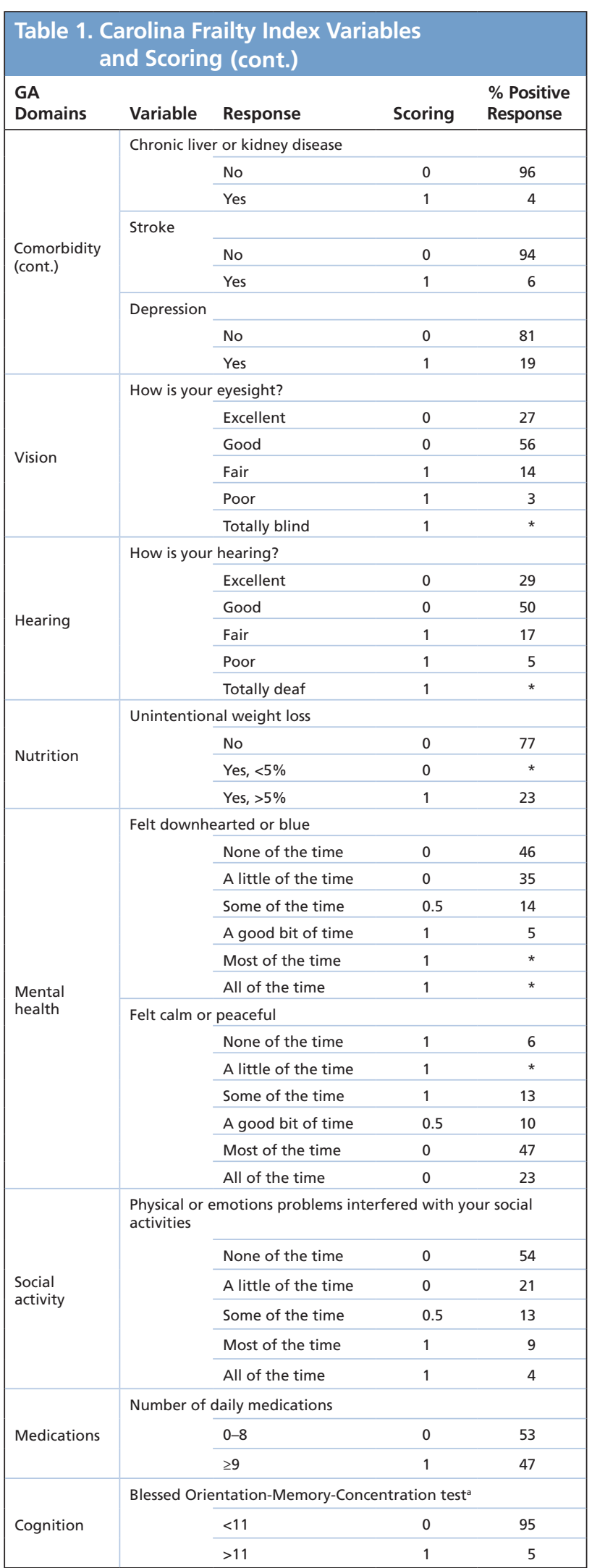

aRequires a healthcare provider to administer and assess. *Cells combined with cell above to preserve confidentiality. 
Guerard et al

(robust, pre-frail, and frail). In addition to evaluating the entire cohort, we also preplanned a subgroup analysis to evaluate patients who completed the GA within 90 days of their cancer diagnosis (incident cancer group). Differences between frailty groups were evaluated using analysis of variance for age and chi-square tests for categorical measures. The Kaplan-Meier method was used to estimate overall survival (OS) and cancer-specific survival from the date of GA completion, and log-rank tests were used to compare survival between frailty groups. A sensitivity analysis was completed to evaluate the relationship of the CFI with all-cause mortality only for those patients with no missing data. Multivariable Cox proportional hazards regression models were used to evaluate the association between frailty and all-cause mortality after controlling for covariates of age, sex, cancer stage and type, and number of medical comorbidities. All analyses were conducted using SAS v9.4 statistical software (Cary, NC).

\section{Results}

\section{Patient Characteristics}

From 2009 to 2014, the CSR enrolled 703 patients from the North Carolina Cancer Hospital who completed the GA. Of those patients, 636 were matched to NCCCR using name, date of birth, and sex $(90 \%$ match rate), of which 553 patients had adequate tumor-specific and survival data; 7 patients were excluded because of missing data, leaving an analytic cohort of 546 patients.

Among the 546 patients (Table 2), the median age was 72 years at the time of the GA (range, 65-100 years). Most patients were female $(n=393$; $72 \%)$, white $(\mathrm{n}=463 ; 85 \%)$, had a breast cancer diagnosis $(n=257 ; 47 \%)$, had stage 0 -II disease $(n=295 ; 54 \%)$, and had at least a high school education $(n=506 ; 92 \%) ; 179$ patients $(33 \%)$ completed the GA within 90 days of their date of diagnosis (incident cancer group).

\section{Frailty}

Using the 36 -item CFI, $58 \%$ of patients $(\mathrm{N}=318)$ were categorized as robust, $24 \%(\mathrm{~N}=131)$ as pre-frail, and $18 \%(\mathrm{~N}=97)$ as frail (Figure 1). Increasing age $(P \leq .001)$, nonwhite race $(P=.02)$, lowwer education $(P \leq .001)$, and cancer type $(P=.002)$ were associated with increasing levels of frailty (Table 2 ). For cancer type, $29 \%$ of patients with lung and bronchus cancers, $23 \%$ of those with hematologic malignancies, and $14 \%$ of those with breast cancer were categorized as frail. For race, $28 \%$ of nonwhite patients were categorized as frail compared with $16 \%$ of white patients. Importantly, cancer stage was not significantly associated with frailty $(P=.13)$.

\section{Frailty and Mortality}

In our sample of 546 patients, 191 deaths (35\%) were observed from any cause, among which 143 (26\%) were cancer-related. Median follow-up of the cohort was 3.7 years (range, 0.9-5.7 years). Median OS in patients categorized as frail was 1.6 years $(95 \% \mathrm{CI}$, 1.14-3.22). Median OS in those categorized as prefrail or robust was not met at the time of this analysis. The estimated 5-year OS was 72\% (95\% CI, 66\%$77 \%$ ) in robust patients, 58\% (95\% CI, 48\%-66\%) in pre-frail patients, and 34\% (95\% CI, 24\%-45\%) in frail patients $(P \leq .0001$; Figure $2 \mathrm{~A})$. The estimated cancer-specific survival rate at 5 years was $77 \%(95 \%$ CI, $72 \%-82 \%)$ for robust patients, $68 \%(95 \% \mathrm{CI}$, $59 \%-76 \%)$ for pre-frail patients, and 54\% (95\% CI, $42 \%-64 \%)$ for frail patients $(P \leq .0001)$.

When evaluating the CFI's ability to predict allcause mortality in patients who completed the GA within 90 days of their diagnosis $(\mathrm{N}=179$; incident cancer group), the log-rank test for differences in all-cause mortality between frailty groups remained significant $(P=.001$; Figure $2 B)$. The results of a sensitivity analyses limited to patients with no missing variables on the 36-item CFI resulted in similar findings (data not shown).

Table 3 reports the associations between frailty groups and all-cause mortality based on the CFI for (1) all patients and (2) the incident cancer group. There was a strong relationship observed between increasing frailty and all-cause mortality when measured by the CFI. The unadjusted hazard ratios (HRs) show that patients categorized as frail had more than a 3-fold increased risk of all-cause mortality (HR, 3.34; 95\% CI, 2.39-4.69) compared with those classified as robust. After adjusting for age, sex, cancer type and stage, and number of medical comorbidities, the patients categorized as frail by the CFI had a significantly higher hazard of death compared with robust patients (adjusted HR, 2.36; 95\% CI, 1.51-3.68). The incident cancer group analysis yielded similar results to the entire cohort, with an adjusted HR of 1.98 (95\% 
Frailty and Older Adults With Cancer

\begin{tabular}{|c|c|c|c|c|c|}
\hline Characteristic & $\begin{array}{l}\text { All Patients, n (\%) } \\
\quad \mathrm{N}=546\end{array}$ & $\begin{array}{c}\text { Robust, } n(\%) \\
\quad \mathrm{N}=318\end{array}$ & $\begin{array}{l}\text { Pre-Frail, n (\%) } \\
\quad \mathrm{N}=131\end{array}$ & $\begin{array}{l}\text { Frail, } \mathrm{n}(\%) \\
\quad \mathrm{N}=97\end{array}$ & $P$ Value \\
\hline \multicolumn{6}{|l|}{ Age, $y$} \\
\hline Median & 72 & 71 & 73 & 76 & \multirow{5}{*}{$<.001$} \\
\hline $65-69$ & $208(38)$ & $151(73)$ & 39 (19) & $18(9)$ & \\
\hline $70-74$ & $155(28)$ & $93(60)$ & $36(23)$ & $26(17)$ & \\
\hline $75-79$ & $91(17)$ & $44(48)$ & $26(29)$ & $21(23)$ & \\
\hline$\geq 80$ & $92(17)$ & $30(33)$ & $30(33)$ & $32(35)$ & \\
\hline \multicolumn{5}{|l|}{ Sex } & \multirow{3}{*}{.62} \\
\hline Female & $393(72)$ & $233(59)$ & $90(23)$ & $70(18)$ & \\
\hline Male & $153(28)$ & $85(55)$ & $41(27)$ & $27(18)$ & \\
\hline \multicolumn{5}{|l|}{ Race } & \multirow{3}{*}{.02} \\
\hline White & $463(85)$ & $279(60)$ & $110(24)$ & $74(16)$ & \\
\hline Other & $83(15)$ & $39(47)$ & $21(25)$ & $23(28)$ & \\
\hline \multicolumn{5}{|l|}{ Cancer type } & \multirow{8}{*}{.002} \\
\hline Breast & $257(47)$ & $173(67)$ & $48(19)$ & $36(14)$ & \\
\hline Lung and bronchus & $66(12)$ & $31(47)$ & $16(24)$ & $19(29)$ & \\
\hline Hematologic malignancy & $66(12)$ & $29(44)$ & $22(33)$ & $15(23)$ & \\
\hline Gastrointestinal & $41(8)$ & $20(49)$ & * & * & \\
\hline Genitourinary & $40(7)$ & $26(65)$ & * & * & \\
\hline Head and neck & $31(6)$ & $19(61)$ & * & * & \\
\hline Other & $45(8)$ & $20(44)$ & $45\left(^{*}\right)$ & $27(*)$ & \\
\hline \multicolumn{5}{|l|}{ Cancer stage } & \multirow{6}{*}{.21} \\
\hline Stage 0/1 & $164(30)$ & $106(65)$ & $33(20)$ & $25(15)$ & \\
\hline Stage II & $131(24)$ & $80(61)$ & $28(21)$ & $23(18)$ & \\
\hline Stage III & $86(16)$ & $48(56)$ & $27(31)$ & $11(13)$ & \\
\hline Stage IV & $95(17)$ & $58(61)$ & $16(17)$ & $21(22)$ & \\
\hline Unstaged/Unknown & $70(13)$ & & & & \\
\hline \multicolumn{5}{|l|}{ Medical comorbidities, $\mathrm{n}$} & \multirow{3}{*}{$<.001$} \\
\hline $0-3$ & $376(70)$ & $276(73)$ & $73(19)$ & $27(7)$ & \\
\hline$>4$ & $162(30)$ & $39(24)$ & $55(34)$ & $68(42)$ & \\
\hline \multicolumn{5}{|c|}{ Time from diagnosis to complete GA } & \multirow{5}{*}{.51} \\
\hline$\leq 90$ days & $179(33)$ & $112(63)$ & $33(18)$ & $34(19)$ & \\
\hline 91 days to 1 year & $120(22)$ & $64(53)$ & $33(28)$ & $23(19)$ & \\
\hline $1-3$ years & $108(20)$ & $63(58)$ & $28(26)$ & $17(16)$ & \\
\hline$>3$ years & $139(25)$ & $79(57)$ & $37(27)$ & $23(17)$ & \\
\hline \multicolumn{5}{|l|}{ Educational level } & \multirow{4}{*}{$<.001$} \\
\hline High school graduate or less & $267(49)$ & $129(48)$ & $78(29)$ & $60(22)$ & \\
\hline Associate/Bachelor's degree & $150(28)$ & $102(68)$ & $27(18)$ & $21(14)$ & \\
\hline Advanced degree & $126(23)$ & $85(67)$ & $26(20)$ & $15(12)$ & \\
\hline
\end{tabular}

Abbreviation: GA, geriatric assessment.

*Cells combined with cell below to preserve confidentiality.

CI, 0.99-3.94) of death for frail compared with robust patients. When evaluating cancer-specific mortality for all patients, a strong relationship remained between increasing frailty and cancer-specific mortality, with an adjusted HR of 2.00 (95\% CI, 1.20-3.33) for frail compared with robust patients.

\section{Discussion}

In our sample of older adults with cancer, the CFI developed from a cancer-specific GA was predictive of all-cause mortality in all patients, and remained predictive in those who completed the GA within 90 days of their cancer diagnosis (incident cancer 




Figure 1. Frailty index distribution.

group). In addition, frailty was also predictive of cancer-specific mortality for the entire cohort. Frail patients had more than a 2 -fold increased risk of all-cause mortality compared with robust patients, a finding that was independent of age, sex, cancer type and stage, and number of medical comorbidities.

The CFI is an objective measure of frailty, a geriatric syndrome known to increase the risk of hospitalization, institutionalization, and death. ${ }^{1-5}$ It is important for oncologists to identify frail patients at risk for poor health outcomes, because cancer therapy may increase the risk of developing frailty and disability. ${ }^{24}$ In addition, frailty markers have been shown to be associated with poor treatment tolerance and toxicity in older adults with cancer. ${ }^{25,26}$ A recent study by the Cancer and Aging Research Group showed that frail and pre-frail patients with solid tumors were more likely to have grade 3 chemotherapy-related toxicity, discontinue treatment, and become hospitalized. This study used a 51-item frailty index, which, in addition to GA variables, included laboratory values and demographics. ${ }^{27}$ The CFI, a shorter, nearly all patient-reported frailty index, may better fit the needs of a busy clinical practice for oncologists to objectively identify frailty in older adults with cancer. With the move to electronic medical records across health systems, ideally the CFI-after further validations studies are completed-would be in the form of an electronic tool that captures and analyzes the data in real time.

A recent systematic review in oncology reported that the prevalence of frailty varied considerably in older adults with cancer, ranging widely from $6 \%$ to $86 \%$ depending on the definition of frailty that was used and the population that was studied. ${ }^{28}$ In the review, the phenotype model of frailty or the presence of 2 to 3 GA domain impairments were the most commonly used definitions of frailty. ${ }^{28}$ However, a notable gap remained-only a few studies included in the review reported on the relationship between frailty and outcomes. ${ }^{25,26,29-32}$ In older women with breast cancer, having geriatric domain impairments was associated with poor tolerance to treatment, allcause mortality, and breast cancer-specific survival
A

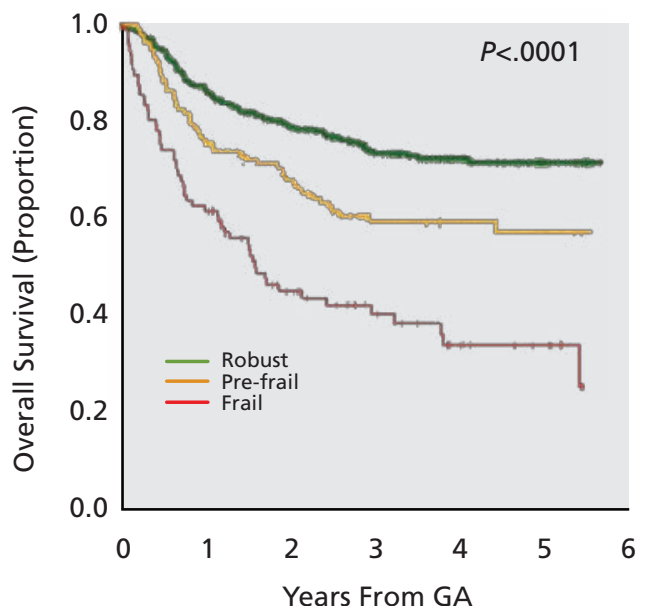

B

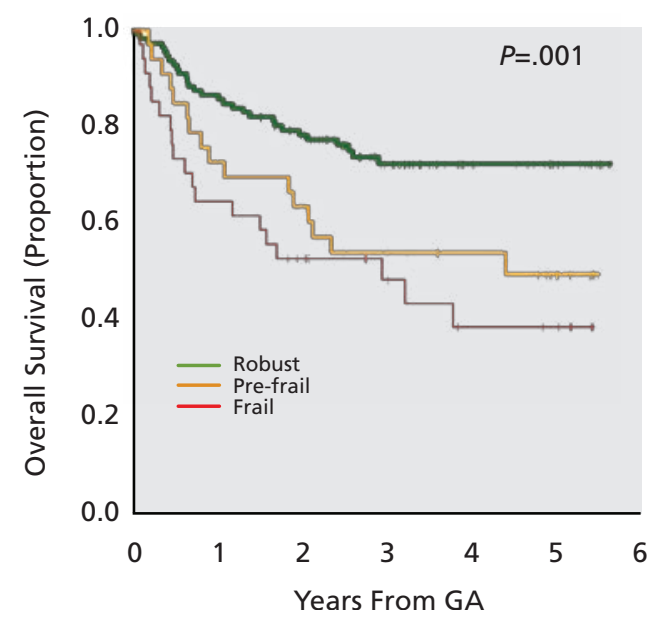

Figure 2. Kaplan-Meier survival curves for all-cause mortality based on the CFI for (A) all patients ( $N=546)$ and (B) the incident cancer group ( $N=179$ ). Abbreviations: CFI, Carolina Frailty Index; GA, geriatric assessment. 
Frailty and Older Adults With Cancer

\begin{tabular}{|c|c|c|c|c|c|c|c|c|c|c|}
\hline \multirow[b]{3}{*}{ CFI Group } & \multicolumn{6}{|c|}{ Events and Mortality Rates by Frailty Groups } & \multicolumn{2}{|c|}{$\begin{array}{l}\text { Unadjusted HRs } \\
\quad(95 \% \mathrm{Cl})\end{array}$} & \multicolumn{2}{|c|}{$\begin{array}{l}\text { Adjusted HRsa } \\
(95 \% \mathrm{Cl}) \\
\end{array}$} \\
\hline & \multicolumn{3}{|c|}{$\begin{array}{l}\text { All Patients } \\
\mathrm{N}=546\end{array}$} & \multicolumn{3}{|c|}{$\begin{array}{l}\text { Incident Cancer Group } \\
\qquad \mathrm{N}=179\end{array}$} & \multirow{2}{*}{$\begin{array}{c}\text { All } \\
\text { Patients } \\
\mathrm{N}=546\end{array}$} & \multirow{2}{*}{$\begin{array}{c}\text { Incident } \\
\text { Cancer } \\
\mathrm{N}=179\end{array}$} & \multirow{2}{*}{$\begin{array}{c}\text { All } \\
\text { Patients } \\
\mathrm{N}=518 \\
\end{array}$} & \multirow{2}{*}{$\begin{array}{c}\text { Incident } \\
\text { Cancer } \\
\mathrm{N}=170\end{array}$} \\
\hline & Death & Total, N & $\mathbf{I R}^{\mathbf{b}}$ & Death & Total, N & $\mathbf{I R}^{\mathbf{b}}$ & & & & \\
\hline Robust & 82 & 318 & 8.5 & 29 & 112 & 9.0 & Ref & Ref & Ref & Ref \\
\hline Pre-frail & 51 & 131 & 14.7 & 16 & 33 & 16.7 & $\begin{array}{l}1.68 \\
(1.18-2.38)\end{array}$ & $\begin{array}{l}1.99 \\
(1.08-3.67)\end{array}$ & $\begin{array}{l}1.22 \\
(0.80-1.87)\end{array}$ & $\begin{array}{l}1.42 \\
(0.66-3.07)\end{array}$ \\
\hline Frail & 58 & 97 & 32.5 & 19 & 34 & 25.1 & $\begin{array}{l}3.34 \\
(2.39-4.69)\end{array}$ & $\begin{array}{l}2.73 \\
(1.53-4.88)\end{array}$ & $\begin{array}{l}2.36 \\
(1.51-3.68)\end{array}$ & $\begin{array}{l}1.98 \\
(0.99-3.94)\end{array}$ \\
\hline
\end{tabular}

Abbreviations: CFI, Carolina Frailty Index; HRs, hazard ratios; IR, incidence rate.

adjusted for age, sex, cancer type and stage, and number of medical comorbidities (unknown stage was excluded from this model).

${ }^{\mathrm{b}}$ Reported per 100-person years.

at 10 years..$^{25,29}$ Several studies from the surgical oncology literature have used different frailty assessment tools to predict 30-day postoperative morbidity and/or mortality. ${ }^{30-37}$ The deficit accumulation model of frailty has not been extensively studied in older adults with cancer and has several clinical practice advantages over the phenotype model. Specifically, the deficit accumulation model of frailty does not require special instrumentation (eg, handheld dynamometers) to complete, nor does it rely on a research-oriented questionnaire. The CFI, constructed from the most widely used and tested cancer-specific GA, ${ }^{15}$ is a practical method for defining oncologic frailty, and this study provides evidence for a validated clinical model of frailty specific to older adults with cancer.

Our study has limitations. Most patients in the CSR have early-stage cancers and most have a breast cancer diagnosis. This may limit the generalizability of our CFI to the broader spectrum of cancer types and stages. More validation is warranted in other cancer populations. Even though our sample consisted largely of patients with breast cancer, the percentage of patients who were frail was similar to what has been reported in the older adult community (14\%). ${ }^{38}$ In addition, findings from our study may not be generalizable due to the lack of sociodemographic diversity. Our study also has important strengths. The combined CSR-NCCCR is a unique and novel data set that brings together detailed information from a cancer-specific GA, which allows for construction of the frailty index, with cancer-specific and long-term mortality data.
This data linkage allows for passive, long-term follow-up of clinical outcomes.

The use of the GA and frailty measures to individualize treatment decisions is of great interest. The CFI may have utility in the future to design GAbased treatment trials after further validation studies are completed. The CFI may also provide a better measure of performance status than traditional measures currently used in clinical trials, ${ }^{8}$ because age or standard performance status measures do not provide an accurate estimation of functional age. ${ }^{7-9}$ The CFI also provides an overall scoring system for the GA that can be easily and quickly interpreted.

\section{Conclusions}

Our study provides the first step in validating a clinical model of frailty for older adults with cancer. The term "frail older adult with cancer" is commonly used, and having an objective definition of this physiologic state is critical to operationalizing the term. The CFI constructed from a cancer-specific GA was predictive of all-cause and cancer-specific mortality in a heterogeneous group of older adults with cancer. Further validation and investigation is warranted by cancer type and stage before it can be more widely applied across cancer populations. The CFI is a practical way to define oncologic frailty and has the potential to be used with ease in busy clinics to help oncologists personalize treatment decisions for older adults and identifying subgroups that may benefit from targeted frailty interventions. 
Guerard et al

\section{References}

1. Rockwood K, Mitnitski A, Song X, et al. Long-term risks of death and institutionalization of elderly people in relation to deficit accumulation at age 70. J Am Geriatr Soc 2006;54:975-979.

2. Song X, Mitnitski A, Rockwood K. Prevalence and 10-year outcomes of frailty in older adults in relation to deficit accumulation. J Am Geriatr Soc 2010;58:681-687.

3. Fried LP, Tangen CM, Walston J, et al. Frailty in older adults: evidence for a phenotype. J Gerontol A Biol Sci Med Sci 2001;56:M146-156.

4. Saum KU, Dieffenbach AK, Muller H, et al. Frailty prevalence and 10-year survival in community-dwelling older adults: results from the ESTHER cohort study. Eur J Epidemiol 2014;29:171-179.

5. Mitnitski AB, Mogilner AJ, MacKnight $\mathrm{C}$, et al. The mortality rate as a function of accumulated deficits in a frailty index. Mech Ageing Dev 2002;123:1457-1460.

6. Clegg A, Young J, Iliffe S, et al. Frailty in elderly people. Lancet 2013;381:752-762.

7. Walter LC, Covinsky KE. Cancer screening in elderly patients: a framework for individualized decision making. JAMA 2001;285:2750-2756.

8. Repetto L, Fratino L, Audisio RA, et al. Comprehensive geriatric assessment adds information to Eastern Cooperative Oncology Group performance status in elderly cancer patients: an Italian Group for Geriatric Oncology study. J Clin Oncol 2002;20:494-502.

9. Jolly TA, Deal AM, Nyrop KA, et al. Geriatric assessment-identified deficits in older cancer patients with normal performance status. Oncologist 2015;20:379-385.

10. Smith BD, Smith GL, Hurria A, et al. Future of cancer incidence in the United States: burdens upon an aging, changing nation. J Clin Oncol 2009;27:2758-2765.

11. Rockwood K, Mitnitski A. Frailty in relation to the accumulation of deficits. J Gerontol A Biol Sci Med Sci 2007;62:722-727.

12. Searle SD, Mitnitski A, Gahbauer EA, et al. A standard procedure for creating a frailty index. BMC Geriatr 2008;8:24.

13. Cigolle CT, Ofstedal MB, Tian Z, et al. Comparing models of frailty: the Health and Retirement Study. J Am Geriatr Soc 2009;57:830-839.

14. Rockwood K, Andrew M, Mitnitski A. A comparison of two approaches to measuring frailty in elderly people. J Gerontol A Biol Sci Med Sci 2007;62:738-743.

15. Hurria A, Gupta S, Zauderer M, et al. Developing a cancer-specific geriatric assessment: a feasibility study. Cancer 2005;104:1998-2005.

16. Extermann M, Aapro M, Bernabei R, et al. Use of comprehensive geriatric assessment in older cancer patients: recommendations from the task force on CGA of the International Society of Geriatric Oncology (SIOG). Crit Rev Oncol Hematol 2005;55:241-252.

17. Dotan E, Walter LC, Baumgartner J, et al. NCCN Clinical Practice Guidelines in Oncology: Older Adult Oncology. Version 2.2017. Accessed June 2, 2017. To view the most recent version of these guidelines, visit NCCN.org.

18. Hurria A, Togawa K, Mohile SG, et al. Predicting chemotherapy toxicity in older adults with cancer: a prospective multicenter study. J Clin Oncol 2011;29:3457-3465.

19. Extermann M, Boler I, Reich RR, et al. Predicting the risk of chemotherapy toxicity in older patients: the Chemotherapy Risk Assessment Scale for High-Age Patients (CRASH) score. Cancer 2012;118:3377-3386.

20. Williams GR, Deal AM, Jolly TA, et al. Feasibility of geriatric assessment in community oncology clinics. J Geriatr Oncol 2014;5:245-251.

21. Hurria $A$, Cirrincione $C T$, Muss $H B$, et al. Implementing a geriatric assessment in cooperative group clinical cancer trials: CALGB 360401. J Clin Oncol 2011;29:1290-1296.
22. Podsiadlo D, Richardson S. The timed "Up \& Go": a test of basic functional mobility for frail elderly persons. J Am Geriatr Soc 1991;39:142-148.

23. Katzman R, Brown T, Fuld P, et al. Validation of a short OrientationMemory-Concentration test of cognitive impairment. Am J Psychiatry 1983;140:734-739.

24. Bylow K, Hemmerich J, Mohile SG, et al. Obese frailty, physical performance deficits, and falls in older men with biochemical recurrence of prostate cancer on androgen deprivation therapy: a case-control study. Urology 2011;77:934-940.

25. Clough-Gorr KM, Stuck AE, Thwin SS, et al. Older breast cancer survivors: geriatric assessment domains are associated with poor tolerance of treatment adverse effects and predict mortality over 7 years of follow-up. J Clin Oncol 2010;28:380-386.

26. Puts MT, Monette J, Girre V, et al. Are frailty markers useful for predicting treatment toxicity and mortality in older newly diagnosed cancer patients? Results from a prospective pilot study. Crit Rev Oncol Hematol 2011;78:138-149.

27. Cohen HJ, Smith D, Sun CL, et al. Frailty as determined by a comprehensive geriatric assessment-derived deficit-accumulation index in older patients with cancer who receive chemotherapy. Cancer 2016;122:3865-3872.

28. Handforth C, Clegg A, Young C, et al. The prevalence and outcomes of frailty in older cancer patients: a systematic review. Ann Oncol 2015;26:1091-1101.

29. Clough-Gorr KM, Thwin SS, Stuck AE, et al. Examining five- and tenyear survival in older women with breast cancer using cancer-specific geriatric assessment. Eur J Cancer 2012;48:805-812.

30. Courtney-Brooks M, Tellawi AR, Scalici J, et al. Frailty: an outcome predictor for elderly gynecologic oncology patients. Gynecol Oncol 2012;126:20-24

31. Tan KY, Kawamura YJ, Tokomitsu A, et al. Assessment for frailty is useful for predicting morbidity in elderly patients undergoing colorectal cancer resection whose comorbidities are already optimized. Am J Surg 2012;204:139-143.

32. Kristjansson SR, Nesbakken A, Jordhoy MS, et al. Comprehensive geriatric assessment can predict complications in elderly patients after elective surgery for colorectal cancer: a prospective observational cohort study. Crit Rev Oncol Hematol 2010;76:208-217.

33. Chappidi MR, Kates M, Patel HD, et al. Frailty as a marker of adverse outcomes in patients with bladder cancer undergoing radical cystectomy. Urol Oncol 2016;34:256.e1-6.

34. Choi JY, Yoon SJ, Kim SW, et al. Prediction of postoperative complications using multidimensional frailty score in older female cancer patients with American Society of Anesthesiologists physical status class 1 or 2. J Am Coll Surg 2015;221:652-660.e2.

35. Lascano D, Pak JS, Kates M, et al. Validation of a frailty index in patients undergoing curative surgery for urologic malignancy and comparison with other risk stratification tools. Urol Oncol 2015;33:426.e1-12.

36. Tegels JJ, de Maat MF, Hulsewe KW, et al. Value of geriatric frailty and nutritional status assessment in predicting postoperative mortality in gastric cancer surgery. J Gastrointest Surg 2014;18:439-445; discussion 445-446.

37. Revenig LM, Canter DJ, Kim S, et al. Report of a simplified frailty score predictive of short-term postoperative morbidity and mortality. J Am Coll Surg 2015;220:904-911.e1.

38. Bandeen-Roche K, Seplaki CL, Huang J, et al. Frailty in older adults: a nationally representative profile in the United States. J Gerontol A Biol Sci Med Sci 2015;70:1427-1434. 